\title{
Putatively lethal ingestion of isopropyl alcohol-related case: interpretation of post mortem isopropyl alcohol and acetone concentrations remains challenging
}

\author{
Carine Dumollard ${ }^{1}$. Jean-François Wiart ${ }^{1} \cdot$ Florian Hakim $^{1,2} \cdot$ Christophe Demarly $^{3}$ - Philippe Morbidelli ${ }^{3}$. \\ Delphine Allorge ${ }^{1,2} \cdot$ Jean-Michel Gaulier ${ }^{1,2}$ (D)
}

Received: 11 May 2020 / Accepted: 14 October 2020 / Published online: 22 October 2020

(C) Springer-Verlag GmbH Germany, part of Springer Nature 2020

\begin{abstract}
Isopropyl alcohol, or propan-2-ol (IPA), is found in numerous chemicals including alcohol-based hand rubs whose use has been recently widely extended to the general population since the onset of the COVID-19 pandemic. This widespread of IPA use could potentially, but not necessarily, be responsible for an increase in IPA poisoning cases (e.g., in alcoholics and/or for suicide attempt, even more in a lockdown situation). Forensic identification of IPA-related fatalities remains challenging as IPA post mortem detection can also result from antemortem or post mortem production, or post mortem contamination. In order to illustrate this issue, we report the case of a 33-year-old man found dead with a bottle of pure IPA liquid close to him. Toxicological positive results only consisted in IPA $(464,260,465$ and $991 \mathrm{mg} / \mathrm{L})$ and acetone $(1560,2340,3040$ and $1360 \mathrm{mg} / \mathrm{L}$ ) in blood, vitreous humour, urine and bile, respectively (determinations using headspace gas chromatography with flame ionization detection). These IPA absolute concentrations and IPA-to-acetone ratios appear inferior to those usually reported in the literature (higher than $1000 \mathrm{mg} / \mathrm{L}$ and 1.1, respectively) in IPA poisoning cases. In conclusion, this death can be cautiously regarded as an IPA ingestion-related fatality in the hypothesis of a survival time which have promoted IPA metabolism to acetone: this hypothesis is supported by the putative limited IPA-ingested dose. This report emphasizes the fact that post mortem IPA and acetone concentration interpretation involves to take account of (i) results in multiple biological specimens, (ii) complete case history, and (iii) a search of possible IPA presence at the scene of death.
\end{abstract}

Keywords Forensic $\cdot$ Toxicology $\cdot$ Fatality $\cdot$ Isopropanol $\cdot$ Acetone

\section{Introduction}

Isopropyl alcohol, propan-2-ol, or isopropanol (IPA) is a flammable and colourless liquid with a fruity odour and a slightly bitter taste. Cheap and easy to obtain, IPA is found in numerous industrial and household chemicals. As a result, IPA can be present in hand sanitizers or alcohol-based hand rubs (ABHRs that typically contain combination of alcohols:

Jean-Michel Gaulier

jean-michel.gaulier@chru-lille.fr

CHU Lille, Unité Fonctionnelle de Toxicologie, Lille, France

2 ULR 4483 - IMPECS - IMPact de l'Environnement Chimique sur la Santé humaine, Univ. Lille, Lille, France

3 CHU Lille, Service de Médecine Légale, Lille, France
IPA, ethanol and/or n-propanol), and also in home cleaning products, disinfectants, antifreezes, cosmetics, solvents and skin lotions... [1]. It is noteworthy that since the onset of the influenza A (H1N1) pdm09 virus epidemic, ABHR use has recently been extended worldwide from healthcare staff to the general population. This ABHR widespread use opens up the possibility of an increase of IPA poisoning cases (e.g. in alcoholics and/or for suicide attempt, even more in a containment situation) as ABHRs are usually available in bottles that facilitate the ingestion of large amounts of liquids [2, 3].

Several IPA intoxication case reports can be found in the literature (including some ABHR ingestion-related cases observed during an $\mathrm{H} 1 \mathrm{~N} 1$ pandemic) and treatment consists essentially on supportive therapy [2-7]. IPA intoxications can be fatal, but only few fatalities have been previously reported [8-14]. In these published fatalities, observed IPA and acetone (its main metabolite) post mortem blood concentrations 
ranged from 200 to $37,000 \mathrm{mg} / \mathrm{L}$ and from 320 to 3000 , respectively, and blood IPA-to-acetone ratio ranged from 0.33 to 25 .

In practice, the interpretation of post mortem toxicological findings in order to diagnose IPA poisoning is tricky in forensic situations. Indeed, IPA post mortem detection in itself cannot be regarded as an evidence of antemortem IPA ingestion by the victim. The main hurdle is that quantifiable concentrations of IPA in post mortem biological fluids can have various origins: endogenous origin (i.e. acetone metabolism), post mortem contamination or production $[11,12,15]$. In this context, we report a fatality putatively related to an IPA poisoning in order to illustrate these interpretation pitfalls.

\section{Case history}

A 33-year-old man was found dead in his closed home. The victim had a past history of drug addiction, psychosis and an attempt of hanging himself. Several items were found close to the corpse: a knife, a cord, a letter and an unlabeled plastic bottle (1.5 L capacity) containing about $1.1 \mathrm{~L}$ of a colourless liquid. Autopsy took place 5 days after the death: this long delay can be explained by the fact that the death occurred just before a weekend, then the corpse (maintained at $+4{ }^{\circ} \mathrm{C}$ ) had to be transported to the Institute of Legal Medicine, around $200 \mathrm{~km}$ from the place of death, and the autopsy was finally achieved on the following Tuesday. Autopsy revealed a beginning state of putrefaction, a pulmonary edema and multivisceral congestion (lungs, liver and kidneys). Neither natural diseases nor traumatic lesions were found. Autopsy examination attributed the fatality to a significant asphyxia syndrome possibly from a toxic origin in the context of a suicide attempt. Femoral (peripheral) blood could not be collected in this victim due to coagulation process and putrefaction phenomena, due to the relatively long delay between death and autopsy ( 5 days). Biological samples (cardiac blood collected in $2 \%$ sodium fluoride tube, vitreous humour, urine, bile and gastric content) were sent to the laboratory in glasssealed tubes for toxicological analyses, together with the unknown liquid contained in the bottle.

\section{Material and methods}

Toxicological investigations consisted in comprehensive screenings of drugs and toxic compounds and were carried out in each biological sample and the unknown liquid using two published methods that are routinely used in forensic contexts in our laboratory [16-19]: (1) a liquid chromatography with high-resolution mass spectrometry detection method (LC-HRMS) using a homemade spectral library of more than
1650 substances and (2) a liquid chromatography with tandem mass spectrometry detection method (LC-MS/MS) for several classes of therapeutic drugs, drugs of abuse (DOA) and other toxicants.

More selective assays for several classes of therapeutic drugs, DOA and other toxicants were also performed using various methods: immunoassays, headspace gas chromatography with flame ionization detection (HS-GC-FID) and LCMS/MS. In particular, a NF EN ISO 15189-accredited (scope no 8-3030 available on website www.cofrac.fr) HS-GC-FID method was used for alcohols and acetone identification and quantification. Briefly, $200 \mu \mathrm{L}$ of biological samples and $200 \mu \mathrm{L}$ of internal standard $(150 \mu \mathrm{L}$ of acetonitrile in $100 \mathrm{~mL}$ of water) were introduced in a 22-mL HS vial, which was rapidly sealed with a silicone septum and aluminium cap. Separation was done in a $624 \mathrm{CB}$ column $(1.8 \mu \mathrm{m} ; 30 \mathrm{~m} \times 0$. $32 \mathrm{~mm}$ i.d.; Varian, Courtaboeuf, France) and detection was performed using a GC2010 Plus (Shimadzu, Marne-la-Vallée, France). For both IPA and acetone, the limit of detection (LOD) and the lower limit of quantification (LLOQ) in whole blood are estimated at 10 and $50 \mathrm{mg} / \mathrm{L}$, respectively; standard curves are linear from 50 to $5000 \mathrm{mg} / \mathrm{L}$, and interday $\mathrm{CV}$ and bias were less than $15 \%$.

\section{Results}

Neither drugs nor DOA were detected in biological samples and the unknown liquid. In particular, ethanol was negative and urinary ethyl glucuronide (a specific metabolite of ethanol) concentration was less than $0.1 \mathrm{mg} / \mathrm{L}$. Positive results only consisted in IPA and acetone detection at high concentrations in all biological samples (Table 1). IPA was also found in the unknown liquid at a concentration of $785 \mathrm{~g} / \mathrm{L}$ (i.e. $>99 \%$ if expressed as a volume percent).

\section{Discussion}

After ingestion, IPA is rapidly absorbed and metabolized by alcohol dehydrogenases to acetone resulting in ketosis and ketonuria [20,21]. Mechanism of isopropanol toxicity is not fully elucidated but both IPA (mainly) and acetone contribute to central nervous system (CNS) depression [7]. The major toxic contribution of IPA itself is supported by several case reports that have shown clinical improvement while acetone blood concentrations were still rising [22-25]. IPA blood elimination half-life varies from 2.5 to $8 \mathrm{~h}$ and a small part is directly eliminated unchanged in urine and breath $[1,5]$. Acetone (blood elimination half-life averages about $22 \mathrm{~h}$ ) is also partially eliminated unchanged in urine and breath. Data supporting formation of formate (and acetate) from acetone remain scarce, and this formation may be negligible. Indeed, 
Table 1 Isopropanol and acetone concentrations in post mortem biological samples $(\mathrm{mg} / \mathrm{L})$

\begin{tabular}{llllll}
\hline & Cardiac blood & Vitreous humour & Urine & Bile & $\begin{array}{l}\text { Gastric content } \\
\text { (total volume: } 100 \mathrm{~mL} \text { ) }\end{array}$ \\
\hline Isopropanol & 464 & 260 & 465 & 991 & 230 \\
Acetone & 1590 & 2340 & 3040 & 1360 & 2130 \\
$\begin{array}{l}\text { Isopropanol-to-acetone } \\
\text { ratio }\end{array}$ & 0.29 & 0.11 & 0.15 & 0.73 & 0.11 \\
\hline
\end{tabular}

elevation of osmolar gap can be observed in cases of IPA intoxication but metabolic acidosis has never been reported [7]. Moreover, acetone can be reduced to isopropanol, which is considered as a physiological minor pathway that can be enhanced in some pathological conditions such as diabetic ketoacidosis $[12,15,26]$. Owing to IPA fast absorption, clinical signs of poisoning occur rapidly, starting with digestive troubles (nausea, abdominal pain, vomiting, hematemesis) and further complicating by hypotension, CNS depression (headaches, dizziness, confusion) and coma $[1,4]$.

The lethal dose of pure IPR is estimated to be around 200$400 \mathrm{~mL}[8,9]$. In such case of IPA intoxication-related death, no specific organic lesions are found at autopsy. Common findings include pulmonary congestion and moderate to extensive bilateral pulmonary haemorrhage $[8,9]$. This is coherent with autopsy findings (i.e. pulmonary edema and multivisceral congestion) in our present case.

In our opinion, in case of IPA positive post mortem results, interpretation should be considered from two points of view: analytical findings in cases of documented IPA poisoning and analytical findings (including IPA presence) in circumstances that are not related to antemortem IPA poisoning. Nevertheless, these two points of view need clarification considering the very few studies available in the literature and their provided data that are barely comparable (Table 2).

\section{IPA and acetone findings in post mortem cases related to documented IPA poisoning}

Concerning toxicological findings, in 1962, Adelson had already reported IPA blood concentrations ranging from 200 to $2000 \mathrm{mg} / \mathrm{L}$ in five fatalities, together with acetonuria as a constant laboratory finding [8]. Nowadays, acetone presence ( $>100 \mathrm{mg} / \mathrm{L}$ ) is considered as a blood marker in cases of IPA poisoning (with the understanding that acetone presence is not specific of IPA poisoning) $[9,26]$. In a retrospective study, Alexander et al. reported 57 cases in which toxicological investigations revealed IPA presence with post mortem blood concentrations ranging from 100 to $4700 \mathrm{mg} / \mathrm{L}$ (mean: $2400 \mathrm{mg} / \mathrm{L}$ ) together with acetone blood concentrations ranging from < 100 to $3200 \mathrm{mg} / \mathrm{L}$ (mean: $1240 \mathrm{mg} / \mathrm{L}$ ) [9]. In fact, only 31 out of these 57 cases could be substantiated as resulting from IPA poisoning alone. In these 31 cases, IPA blood concentrations ranged from 100 to $2500 \mathrm{mg} / \mathrm{L}$ (mean:
$1400 \mathrm{mg} / \mathrm{L}$ ) and acetone blood concentrations ranged from 400 to $3000 \mathrm{mg} / \mathrm{L}$ (mean: $1700 \mathrm{mg} / \mathrm{L}$ ). Accordingly, IPA and acetone blood concentrations did not appear to be effective tools to distinguish IPA poisoning to other causes of death.

In 2010, Molina reported eight cases of fatal IPA intoxications with high IPA blood concentrations ranging from 1480 to $37,000 \mathrm{mg} / \mathrm{L}$ (median: $1750 \mathrm{mg} / \mathrm{L}$ ) and acetone blood concentrations ranging from 400 to $2000 \mathrm{mg} / \mathrm{L}$ (median: 1500) [12]. The average IPA-to-acetone ratio was 5.5 (range 0.8-25) in blood samples and 5.6 (range 1.0-18.6) in vitreous humour samples. In seven out of the eight cases, IPA blood concentration was greater than that of acetone, and IPA blood and vitreous humour concentrations were above $1000 \mathrm{mg} / \mathrm{L}$. In six other IPA poisoning cases, Petersen et al. also reported high post mortem IPA blood concentrations (ranging from 500 to $6500 \mathrm{mg} / \mathrm{L}$ ) together with high IPA-to-acetone ratios (mean: 3.70) [14].

These latter reports are not consistent with our present case where IPA concentration and IPA-to-acetone ratios are $464 \mathrm{mg} / \mathrm{L}$ and 0.29 in blood and $260 \mathrm{mg} / \mathrm{L}$ and 0.11 in vitreous humour, respectively. Nevertheless, as suggested by Jenkins et al. and Gaulier et al., low IPA concentration could be observed in post mortem blood from IPA-intoxicated victims who have survived long enough for IPA to be metabolized to acetone $[11,13]$. Indeed, this survival time between ingestion and death should be considered for interpretation. The blood kinetics of IPA and acetone had been studied in six non-fatal cases after IPA ingestion [20]: IPA-to-acetone ratio decreases from the fifth hour after ingestion. Unfortunately, this major issue about survival time was unavailable in published post mortem reports. Merricks et al. also reported a case of IPA poisoning with cardiac blood concentrations for IPA $(370 \mathrm{mg} / \mathrm{L})$ and acetone $(320 \mathrm{mg} / \mathrm{L})$ that were in the low range of (or lower than) values reported by Alexander and Molina. The same authors reported another fatality for which IPA bottles were found at the scene. In this case, IPA/acetone post mortem concentrations were close to those observed in our present case: $880 / 1960 \mathrm{mg} / \mathrm{L}$ in femoral blood, 640/ $1960 \mathrm{mg} / \mathrm{L}$ in cardiac blood, 760/2990 mg/L in urine and $550 / 2510 \mathrm{mg} / \mathrm{L}$ in vitreous humour [11]. Lastly, in another fatality related to both hypothermia and IPA intoxication (bottle of rubbing alcohol present at the scene), IPA/acetone post mortem concentrations were also close to those of the 


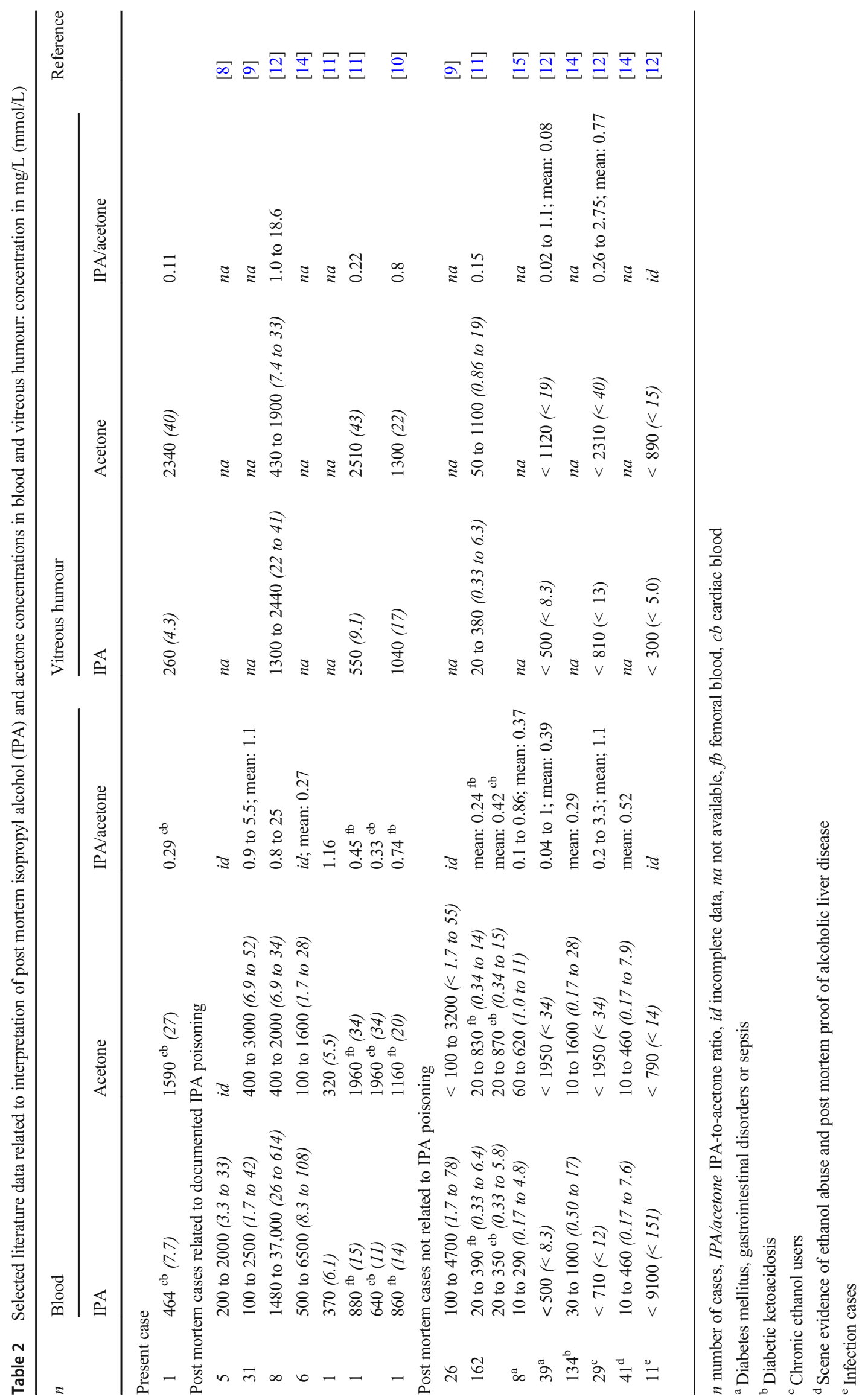


presented case: $860 / 1160 \mathrm{mg} / \mathrm{L}$ in femoral blood and $1040 / 1300 \mathrm{mg} / \mathrm{L}$ in vitreous humour [10].

Furthermore, some other reports of specific intoxication cases where IPA was an ingredient of an ingested mixture should be noted (PineSoil ${ }^{\mathrm{TM}}$ ), but finally not considered as the main toxicant related to the cause of death. In two fatalities, 1-alpha-terpineol, the major terpene alcohol of pine oil, was reported to be the main toxicant $[27,28]$.

To summarize, in post mortem cases related to documented IPA intoxication, acetone is also and always detected in biological fluids, IPA blood concentrations seem regularly high and exceeding $1000 \mathrm{mg} / \mathrm{L}$ and IPA-to-acetone ratios are usually over 1.1 in blood and vitreous humour (this latter specimen even appears to be the most appropriate matrix as it demonstrates a weaker ratio variability than blood). However, an IPA poisoning hypothesis should not be discounted when a low IPA post mortem concentration $(<$ $1000 \mathrm{mg} / \mathrm{L}$ ) and/or IPA-to-acetone ratio $<1.1$ are observed, in particular if the case history suggests a significant survival time and/or reports a potential source of exposure to IPA (as in the present case with the presence of a bottle of pure IPA close to the corpse) [11].

\section{IPA and acetone findings in post mortem cases not related to IPA poisoning}

Due to various circumstances such as IPA antemortem or post mortem production as well as post mortem contamination, the detection of IPA in post mortem samples is thus not a formal evidence of IPA antemortem exposure [12]. As aforementioned, 26 out of the 57 cases reported by Alexander et al. were not related to IPA intoxication: in these cases, post mortem blood IPA (range: 100 to $4700 \mathrm{mg} / \mathrm{L}$ ) and acetone (range: $<100$ to $3200 \mathrm{mg} / \mathrm{L}$ ) concentrations were not significantly different from those observed in the 31 cases of documented IPA poisoning [9]. In a larger series comprising 162 cases not related to IPA intoxication, Jenkins et al. reported post mortem concentrations ranging from 20 to $390 \mathrm{mg} / \mathrm{L}$ (IPA) and from 20 to $830 \mathrm{mg} / \mathrm{L}$ (acetone) in femoral blood, from 20 to $350 \mathrm{mg} / \mathrm{L}$ (IPA) and from 20 to $870 \mathrm{mg} / \mathrm{L}$ (acetone) in cardiac blood, from 20 to $380 \mathrm{mg} / \mathrm{L}$ (IPA) and from 50 to $1100 \mathrm{mg} / \mathrm{L}$ (acetone) in vitreous humour, and from 20 to $380 \mathrm{mg} / \mathrm{L}$ (IPA) and from 50 to $1300 \mathrm{mg} / \mathrm{L}$ (acetone) in urine. In this study, observed IPA concentrations and IPA-to acetone ratios (mean: 0.42 in cardiac blood, 0.24 in femoral blood, 0.15 in vitreous humour and 0.20 in urine) are definitely lower than in cases of documented IPA poisoning and it is concluded that the presence of IPA is the consequence of acetone metabolism (embalmed and decomposed cases were excluded from the study) [11].

There are several situations leading to IPA antemortem production from acetone. The main one is diabetic ketoacidosis where insulin deficiency and glucagon excess lead to hyperglycaemia, production of ketone bodies including acetone and acidosis [14, 29]. Davis et al. were the first to confirm and demonstrate IPA production from acetone reduction [15]. Furthermore, these authors reported IPA and acetone post mortem blood concentrations ranging from 10 to $290 \mathrm{mg} / \mathrm{L}$ and from 60 to $620 \mathrm{mg} / \mathrm{L}$, respectively, in eight decedents with history of diabetes mellitus, gastrointestinal disorders or sepsis, but without antemortem exposure to IPA. Molina reported 39 cases of diabetes mellitus with post mortem concentrations up to $500 \mathrm{mg} / \mathrm{L}$ (IPA) and $1950 \mathrm{mg} / \mathrm{L}$ (acetone) in blood and up to $500 \mathrm{mg} / \mathrm{L}$ (IPA) and to $1120 \mathrm{mg} /$ $\mathrm{L}$ (acetone) in vitreous humour. The corresponding IPA-toacetone ratios averaged 0.39 (range: 0.04 to 1.0 ) in blood and 0.08 (range: 0.02 to 1.1 ) in vitreous humour [12]. Petersen et al. reported 134 cases with diabetic ketoacidosis where post mortem IPA blood concentrations (mean: $151 \mathrm{mg} / \mathrm{L}$; range: 30 to $1000 \mathrm{mg} / \mathrm{L}$ ) and IPA-to-acetone ratios (mean: 0.29$)$ were significantly $(p<0.005)$ lower than those observed in six IPA poisoning cases [14].

Associated with excessive ethanol ingestion and poor nutritional intake, alcoholic ketoacidosis constitutes another source of antemortem IPA production consecutive to acetone production from fatty acid and ethanol metabolisms [30, 31]. In 29 chronic ethanol users, Molina reported post mortem concentrations up to $710 \mathrm{mg} / \mathrm{L}$ (IPA) and $1950 \mathrm{mg} / \mathrm{L}$ (acetone) with IPA-to-acetone ratios averaging 1.1 in blood and up to $810 \mathrm{mg} / \mathrm{L}$ (IPA) and $2310 \mathrm{mg} / \mathrm{L}$ (acetone) with IPAto-acetone ratios averaging 0.77 in vitreous humour [12]. Petersen et al. reported 41 cases (scene evidence of ethanol abuse and post mortem proof of alcoholic liver disease) with post mortem IPA blood concentrations (mean: $185 \mathrm{mg} / \mathrm{L}$; range: 100 to $460 \mathrm{mg} / \mathrm{L}$ ) and IPA-to-acetone ratios (mean: $0.52)$ significantly $(p<0.005)$ lower than those observed in six IPA poisoning cases [14]. Overall, these IPA and acetone post mortem concentrations in alcoholic ketoacidosis-related decedents are similar to those observed in cases of diabetes mellitus, although somewhat higher IPA-to-acetone ratios were observed. Nevertheless, in this context of chronic ethanol use, the presence of high concentrations of ethanol in blood and vitreous humour ( $82 \%$ of the 29 cases reported by Molina [12]) samples would help to determine the origin of IPA.

IPA antemortem production from acetone can occur in other physiopathological conditions, such as infections, dehydration, malnutrition or hypothermia. Post mortem IPA concentrations in blood or vitreous humour of dehydrated and/or malnourished decedents appear to be relatively low (below $220 \mathrm{mg} / \mathrm{L})$. Conversely, in infection cases $(n=11)$, Molina reported post mortem IPA concentrations that were relatively high in blood (median: $700 \mathrm{mg} / \mathrm{L}$; up to $9100 \mathrm{mg} / \mathrm{L}$ ), but low in vitreous humour (median $100 \mathrm{mg} / \mathrm{L}$; up to $300 \mathrm{mg} / \mathrm{L}$ ). It is of note that acetone presence (in only $18 \%$ of the cases) was inconstant in these infection-related cases [12]. In 
hypothermia cases, post mortem IPA concentrations remain very low (below $20 \mathrm{mg} / \mathrm{L}$ ) in blood and vitreous humour [32].

Depending on the microorganisms and the substrates that are present, putrefaction phenomenon in decomposed bodies commonly leads to the production of ethanol and other alcohols, comprising IPA and acetone, by bacteria (mostly Escherichia coli, Clostridium perfringens, Enterococcus faecalis and Clostridium sporogenes) or yeasts (mostly Candida albicans and Saccharomyces cerevisiae) [33, 34]. In decomposing bodies, IPA and acetone concentrations seem to be $<1000 \mathrm{mg} / \mathrm{L}$ and $<500 \mathrm{mg} / \mathrm{L}$ in blood and vitreous humour, respectively, whereas IPA-to acetone ratios are more variable. Whatever, low ethanol concentrations and decomposed state of the body are good indicators of probable post mortem IPA production $[12,35]$.

Post mortem contamination by IPA can sometimes occur, mainly in cases of embalming (embalming fluids usually contain methanol, and often isopropanol, formaldehyde or ethanol), and "apparently" in some cases where the body was washed with IPA before post mortem tissue procurement as suggested by Molina [12]. Nevertheless, this post mortem contamination is questionable as penetration of IPA through the intact skin seems hardly observed [36]. Even if IPA post mortem concentrations can be very high in some of these particular cases, the regular absence (over the physiological range) of acetone together with the case history allows the identification of post mortem contamination [12].

Lastly, besides IPA poisoning cases, small amounts of IPA can be sometimes detected in post mortem samples as the consequence of antemortem IPA exposure in some specific situations: e.g. in workers exposed to IPA (inhalation may be a route of exposure which, however, is limited regarding safety at work) or deaths occurring after binge drinking of alcoholic beverages in which IPA is present as a congener of ethanol [37]. However, in such sudden deaths of alcoholics, even if determination of butanol-1 and other congeners is advisable, observed IPA post mortem blood concentrations due to this "congeneric" presence remain low $(<50 \mathrm{mg} / \mathrm{L})$ [38].

To sum up, IPA (+/- acetone) can be detected in post mortem samples from cases not related to IPA poisoning. These situations can be divided in (i) cases where IPA is detected but not acetone (post mortem contamination cases including embalming cases, post mortem tissue procurement), (ii) cases where IPA (+/- acetone) concentration remains low, i.e. regularly $<200 \mathrm{mg} / \mathrm{L}$ (dehydration and/or malnutrition, hypothermia, IPA present as a congener of ethanol) and (iii) cases where IPA and acetone concentrations are sometimes comparable with those observed in IPA poisoning cases (diabetic ketoacidosis, alcoholic ketoacidosis, infections and putrefaction phenomenon). In this latter category, if decomposition can certainly be easily identified (e.g. because of ethanol presence and decomposed state of the body), other situations are not readily identifiable without documented medical history of the victim and/or additional investigations (e.g. microbiological ones in order to identify bacteria or yeasts involved in IPA post mortem production). In order to distinguish these cases from IPA poisoning ones, low concentrations $(<$ $1000 \mathrm{mg} / \mathrm{L}$ ) [12] of IPA both in blood and vitreous humour are frequently helpful, as well as IPA-to-acetone ratios that appear to be regularly, even if not systematically, below 1.0, especially in vitreous humour.

\section{IPA and acetone findings in the reported case}

Beyond autopsy findings (i.e. pulmonary edema and multivisceral congestion) that are not specific but consistent with those observed in cases of IPA poisoning, analytical findings in the reported case are eligible for consideration based on all aforementioned points.

On the one hand, IPA poisoning hypothesis is supported by IPA and acetone presence in all biological samples at not negligible concentrations (greater than $200 \mathrm{mg} / \mathrm{L}$ ) and by the presence of a bottle of pure IPA close to the victim. Nevertheless, two key elements are not supportive of a lethal ingestion of isopropyl alcohol: (1) IPA concentrations (464 mg/L in cardiac blood and, more specifically, $260 \mathrm{mg} /$ $\mathrm{L}$ in vitreous humour) remain clearly below the usually reported ones in IPA poisoning cases (>1000 mg/L) and (2) observed IPA-to-acetone ratios ( 0.29 in cardiac blood and, more specifically, 0.11 in vitreous humour) are also far below expected ones $(>1.1)$. It is noteworthy that the long delay between death and autopsy ( 5 days) could have participated to the decrease of IPA and acetone concentrations and/or to acetone conversion to IPA by bacterial alcohol dehydrogenase [33], even if the corpse was maintained at $+4{ }^{\circ} \mathrm{C}$. Nevertheless, there is no clear data in the literature supporting these hypotheses. Petersen et al. investigated the post mortem interval between death and autopsy, but only a weak correlation between this delay and an upper IPA-to-acetone ratio in diabetic ketoacidosis post mortem cases was observed [14].

On the other hand, even if two previously mentioned categories (cat1 and cat2) of situations not related to IPA poisoning can be here excluded owing the absence of ethanol and both IPA and acetone concentrations over $200 \mathrm{mg} / \mathrm{L}$, another hypothesis (cat3) should be considered: diabetic ketoacidosis, alcoholic ketoacidosis, infections or decomposition. Because of the decomposed state of the body (slight putrefaction) and the absence of ethanol, the hypothesis of a putrefaction phenomenon (leading to a significant increase of IPA and acetone) can reasonably be ruled out. In the present case, IPA blood and vitreous humour concentrations together with IPA-to-acetone ratios are in the range of those observed in other situations (ketoacidosis and infections). There was no available medical information to support (or to exclude) 
possible diabetic ketoacidosis, alcoholic ketoacidosis or infection status in the victim.

All in all, this case can be cautiously considered as related to a lethal ingestion of IPA due to two points: (1) IPA pure liquid (originally of unknown origin) close to the victim and (2) hypothesis of a significant survival time which has promoted IPA metabolism to acetone. Indeed, the possibility of a prolonged agony should be considered considering the probably limited volume of pure IPA ingested by the victim of around $400 \mathrm{~mL}(1100 \mathrm{~mL}$ of IPA was still present in the plastic bottle of $1500-\mathrm{mL}$ capacity).

\section{Conclusion}

The interpretation of post mortem isopropyl alcohol and acetone concentrations, as well as IPA-to-acetone ratios, remains challenging mainly due to overlapping values between documented IPA poisoning cases and other cases not related to IPA poisoning. When isopropanol is detected in post mortem samples, by taking into account analytical findings in multiple biological specimens (and their confrontation with literature data), complete case history and search of possible IPA presence at the scene of death may provide reasonable explanations of a possible cause of death. Finally, in the current situation of the COVID-19 epidemic where ABHRs are more easily accessible, it is noteworthy that in cases of death suspected to be in relation with ABHR ingestion, post mortem detection of other constituents of the liquid (i.e. ethanol and npropanol) simultaneously with IPA and acetone can be helpful for diagnostic [3].

\section{Compliance with ethical standards}

Conflict of interest The authors declare that they have no conflict of interest.

\section{References}

1. Slaughter RJ, Mason RW, Beasley DMG, Vale JA, Schep LJ (2014) Isopropanol poisoning. Clin Toxicol (Phila) 52(5):470478. https://doi.org/10.3109/15563650.2014.914527

2. Tavolacci MP, Marini H, Vanheste S, Merle V, Coulon AM, Micaud G, Czernichow P (2007) A voluntary ingestion of alcohol-based hand rub. J Hosp Infect 66(1):86-87. https://doi. org/10.1016/j.jhin.2007.01.008

3. Skopp G, Gutmann I, Schwarz CS, Schmitt G (2016) An unnatural death by propan-1-ol and propan-2-ol. Int J Legal Med 130(4):975980. https://doi.org/10.1007/s00414-015-1302-3

4. Lacouture PG, Wason S, Abrams A, Lovejoy FH (1983) Acute isopropyl alcohol intoxication. Diagnosis and management. Am J Med 75(4):680-686. https://doi.org/10.1016/0002-9343(83) 90456-4
5. Daniel DR, McAnalley BH, Garriott JC (1981) Isopropyl alcohol metabolism after acute intoxication in humans. J Anal Toxicol 5(3): 110-112. https://doi.org/10.1093/jat/5.3.110

6. Henry-Lagarrigue M, Charbonnier M, Bruneel F, Legriel S, Troche G, Ben Mokhtar H, Yehia A, Guezennec P, Merrer J, Palette C, Bedos JP (2010) Severe alcohol hand rub overdose inducing coma, watch after H1N1 pandemic. Neurocrit Care 12(3):400-402. https://doi.org/10.1007/s12028-009-9319-4

7. Mégarbane B, Villa A (2019) Poisoning with ethanol and 2propanol-based hand rubs: give Caesar what belongs to Caesar! Neurocrit Care 30(1):226-228. https://doi.org/10.1007/s12028010-9353-2

8. Adelson L (1962) Fatal intoxication with isopropyl alcohol (rubbing alcohol). Am J Clin Pathol 38:144-151. https://doi.org/10. 1093/ajcp/38.2.144

9. Alexander CB, McBay AJ, Hudson RP (1982) Isopropanol and isopropanol deaths-ten years' experience. J Forensic Sci 27(3): 541-548. https://doi.org/10.1520/JFS12166J

10. Honey D, Caylor C, Luthi R, Kerrigan S (2005) Comparative alcohol concentrations in blood and vitreous fluid with illustrative case studies. J Anal Toxicol 29(5):365-369. https://doi.org/10.1093/jat/ 29.5.365

11. Jenkins AJ, Merrick TC, Oblock JM (2008) Evaluation of isopropanol concentrations in the presence of acetone in postmortem biological fluids. J Anal Toxicol 32(8):719-720. https://doi. org/10.1093/jat/32.8.719

12. Molina DK (2010) A characterization of sources of isopropanol detected on postmortem toxicologic analysis. J Forensic Sci 55(4):998-1002. https://doi.org/10.1111/j.1556-4029.2010.01386. $\mathrm{x}$

13. Gaulier JM, Lamballais F, Yazdani F, Lachâtre G (2011) Isopropyl alcohol concentrations in postmortem tissues to document fatal intoxication. J Anal Toxicol 35(4):254-255. https://doi.org/10.1093/ anatox/35.4.254

14. Petersen TH, Williams T, Nuwayhid N, Harruff R (2012) Postmortem detection of isopropanol in ketoacidosis. J Forensic Sci 57(3):674-678. https://doi.org/10.1111/j.1556-4029.2011. 02045.x

15. Davis PL, Dal Cortivo LA, Maturo J (1984) Endogenous isopropanol: forensic and biochemical implications. J Anal Toxicol 8(5):209-212. https://doi.org/10.1093/jat/8.5.209

16. Richeval C, Gaulier JM, Romeuf L, Allorge D, Gaillard Y (2019) Case report: relevance of metabolite identification to detect new synthetic opioid intoxications illustrated by U-47700. Int J Legal Med 133(1):133-142. https://doi.org/10.1007/s00414-018-1969-3

17. Gaulier JM, Richeval C, Phanithavong M, Brault S, Allorge D, Dumestre-Toulet V (2019) A case report of carfentanil-related fatality in France. Toxicol Anal Clin 31(4):323-331. https://doi.org/ 10.1016/j.toxac.2019.01.002

18. Lelievre B, Richeval C, Coulon A, Iwanikow D, Brofferio M, Deguigne M, Boels D, Allorge D, Ferec S, Drevin G, Jousset N, Gaulier JM (2020) Case report on two-cathinones abuse: MPHP and N-ethyl-4'methylnorpentedrone, with a fatal outcome. Forensic Toxicol 38:243-254. https://doi.org/10.1007/s11419019-00486-X

19. Wiart JF, Hakim F, Andry A, Eiden C, Drevin G, Lelièvre B, Rougé-Maillart C, Decourcelle M, Lemaire-Hurtel AS, Allorge D, Gaulier JM (2020) Pitfalls of toxicological investigations in hair, bones and nails in extensively decomposed bodies: illustration with two cases. Int J Legal Med. https://doi.org/10.1007/s00414-02002267-3

20. Pappas AA, Ackerman BH, Olsen KM, Taylor EH (1991) Isopropanol ingestion: a report of six episodes with isopropanol and acetone serum concentration time data. J Toxicol Clin Toxicol 29(1):11-21. https://doi.org/10.3109/ 15563659109038593 
21. Nordmann R, Ribiere C, Rouach H, Beauge F, Giudicel Y, Nordmann J (1973) Metabolic pathways involved in oxidation of isopropanol into acetone by intact rat. Life Sci 13:919-932. https:// doi.org/10.1016/0024-3205(73)90082-9

22. Dua SL (1974) Letter: peritoneal dialysis for isopropyl alcohol poisoning. JAMA 230(1):35. https://doi.org/10.1001/jama.1974. 03240010019008

23. Gaudet MP, Fraser GL (1989) Isopropanol ingestion: case report with pharmacokinetic analysis. Am J Emerg Med 7(3):297-299. https://doi.org/10.1016/0735-6757(89)90174-5

24. Mydler TT, Wasserman GS, Watson WA, Knapp JF (1993) Twoweek-old infant with isopropanol intoxication. Pediatr Emerg Care 9(3):146-148. https://doi.org/10.1097/00006565-19930600000007

25. Blanchet B, Charachon A, Lukat S, Huet E, Hulin A, Astier A (2007) A case of mixed intoxication with isopropyl alcohol and propanol-1 after ingestion of a topical antiseptic solution. Clin Toxicol (Phila) 45(6):701-704. https://doi.org/10.1080/ 15563650701517285

26. Jerrard D, Verdile V, Yealy D, Krenzelok E, Menegazzi J (1992) Serum determinations in toxic isopropanol ingestion. Am J Emerg Med 10(3):200-202. https://doi.org/10.1016/0735-6757(92)90208$\mathrm{F}$

27. Cording CJ, Vallaro GM, Deluca R, Camporese T, Spratt E (2000) A fatality due to accidental PineSol ingestion. J Anal Toxicol 24(7): 664-667. https://doi.org/10.1093/jat/24.7.664

28. Martz W (2010) A lethal ingestion of a household cleaner containing pine oil and isopropanol. J Anal Toxicol 34(1):49-52. https:// doi.org/10.1093/jat/34.1.49

29. Bailey DN (1990) Detection of isopropanol in acetonemic patients not exposed to isopropanol. Clin Toxicol 28:459-466. https://doi. org/10.3109/15563659009038588

30. Platteborze PL, Rainey PM, Baird GS (2011) Ketoacidosis with unexpected serum isopropyl alcohol. Clin Chem 57(10):13611344. https://doi.org/10.1373/clinchem.2010.157248

31. Prevost M, Sun Y, Servilla KS, Massie L, Glew RH, Tzamloukas AH (2012) Repeated intoxication presenting with azotemia, elevated serum osmolal gap, and metabolic acidosis with high anion gap: differential diagnosis, management and prognosis. Int Urol Nephrol 44(1):309-314. https://doi.org/10.1007/s11255-010-9796-6

32. Palmiere C, Sporkert F, Werner D, Bardy D, Augsburger M, Mangin P (2012) Blood, urine and vitreous isopropyl alcohol as biochemical markers in forensic investigations. Leg Med (Tokyo) 14(1):17-20. https://doi.org/10.1016/j.legalmed.2011.10.005

33. Boumba VA, Ziavrou KS, Vougiouklakis T (2008) Biochemical pathways generating post-mortem volatile compounds co-detected during forensic ethanol analyses. Forensic Sci Int 174(2-3):133151. https://doi.org/10.1016/j.forsciint.2007.03.018

34. Boumba VA, Economou V, Kourkoumelis N, Gousia P, Papadopoulou C, Vougiouklakis T (2012) Microbial ethanol production: experimental study and multivariate evaluation. Forensic Sci Int 215(1-3):189-198. https://doi.org/10.1016/j.forsciint.2011. 03.003

35. Kugelberg FC, Jones AW (2007) Interpreting results of ethanol analysis in postmortem specimens: a review of the literature. Forensic Sci Int 165:10-29. https://doi.org/10.1016/j.forsciint. 2006.05.004

36. Brown TL, Gamon S, Tester P, Martin R, Hosking K, Bowkett GC, Gerostamoulos D, Grayson ML (2007) Can alcohol-based handrub solutions cause you to lose your driver's license? Comparative cutaneous absorption of various alcohols. Antimicrob Agents Chemother 51(3):1107-1108. https://doi.org/10.1128/AAC. 01320-06

37. Rohsenow DJ, Howland J (2010) The role of beverage congeners in hangover and other residual effects of alcohol intoxication: a review. Curr Drug Abuse Rev 3(2):76-79. https://doi.org/10.2174/ 1874473711003020076

38. Teresiński G, Buszewicz G, Madro R (2009) Acetonaemia as an initial criterion of evaluation of a probable cause of sudden death. Leg Med (Tokyo) 11(1):18-24. https://doi.org/10.1016/j.legalmed. 2008.08.002

Publisher's note Springer Nature remains neutral with regard to jurisdictional claims in published maps and institutional affiliations. 